result in a hospital admission irrespective of variations in local practice. The results were stratified by gender, external cause and intent. Differences were observed across IOBI for all injuries and between various intent and external cause groupings. The interpretation is difficult, as most of this variance is likely to be a result of data artefacts (eg, variability in coding practice) or local practice, rather than true incidence. These are of interest as they highlight variations in data collection mechanisms and practice, but IOBI is refining the specification so that we can provide a far more accurate comparative picture of injury related inpatient admissions across Britain and Ireland.

\title{
0636 ANALYSIS OF INPATIENT ADMISSIONS DATA FOR INJURIES ACROSS BRITAIN AND IRELAND
}

S Barron, P Brown*, A Lee, S Macey, W Slater Correspondence: South West Public Health Observatory, Grosvenor House, 149 Whiteladies Road, Clifton, Bristol BS8 2RA, UK

\subsection{6/ip.2010.029215.636}

The Injury Observatory for Britain and Ireland (IOBI) is a collaborative venture between the Association of Public Health Observatories and several academic institutions across Britain and Ireland. It aims to support injury prevention by making relevant information and tools easily available. Throughout 2009/2010, IOBI have developed a specification which will enable comparative analysis of inpatient data across the five countries. Agreeing consistent case definitions and appropriate methodologies for use across all five nations was a major focus of the work. This was important because inpatient data varied from country to country in terms of availability, definitions, inclusion and exclusion criteria, coding systems, coding practices and reporting timeframes. European Aged Standardised Rates were calculated (to allow comparisons) for all emergency admissions for injury, serious injuries and fractured neck of femur injuries. These were chosen because these are likely to 